\title{
Don't Say "Consciousness": Toward a Uniform Vocabulary of Subjectivity
}

\author{
Bill Meacham \\ Independent Scholar in Philosophy, USA ${ }^{\mathrm{i}}$
}

Copyright $\bigcirc 2016$ by authors, all rights reserved. Authors agree that this article remains permanently open access under the terms of the Creative Commons Attribution License 4.0 International License

\begin{abstract}
The language we use to talk about consciousness, experience, mind, subjectivity and the like is ambiguous. Different people use common terms in different ways without realizing it, and thereby foster confusion. In this paper a terminology is proposed for speaking of subjectivity. An operational definition is given of the term "subjectivity," and from that standpoint usages of the terms "experience," "consciousness" and "awareness" are proposed. The approach is both phenomenological in the tradition of Husserl, examining that which is given directly from a first-person point of view while holding in abeyance interpretive theories, and analytic in the British tradition, attempting to clarify terminology used to discuss what is found in such phenomenological investigation. After proposing definitions of salient terms, suggestions are given for reframing confusing language. To make the speaker's meaning clear it is recommended to avoid the term "consciousness" altogether.
\end{abstract}

Keywords Consciousness, Subjectivity, Philosophy of Mind

\section{Introduction}

Philosophy of mind is a topic fraught with ambiguity. People use terms such as "mind," "consciousness," "awareness," "experience" and so forth as if everyone knows what they mean. But they can mean very different things to different people; too often we end up with ambiguity, equivocation and misunderstanding. Trying to make progress in understanding without a common agreement on the meaning of such terms is hopeless.

As an example, at a recent conference on the science of consciousness the word "consciousness" was used at various times to mean each of the following:

- Being awake, not asleep or sedated

- An occasion or episode of being conscious of something
- Being conscious of things over a span of time

- The general capacity to be conscious of things

- Metaphorically, a sort of container in which various objects and happenings occur

- Metaphorically, the set of objects and happenings in the container

- The fact that there are conscious beings in the world, that the world contains subjective features as well as objective ones

- A conscious self

- The sense of being a conscious self

- The ground of all being

That's quite a list. It is not surprising that misunderstanding abounds despite the appearance of comprehension.

In this paper I propose to impose some order on this chaos by suggesting definitions and ways to use a few salient terms. I do not claim that these are the only correct definitions. I merely claim that if we all agree to use words the same way we'll have a productive conversation rather than talking past each other.

My approach is phenomenological in the sense that I define the various terms from a first-person point of view without reference to explanatory theories. To decide whether my proposed definitions make sense, I ask the reader to examine his or her own experience to see in what way they are applicable.

I do not adjudicate between the many competing theories of how mind is related to physical reality. I only to attempt to get agreement on how to use words such that competing theories, if couched in agreed-upon language, can be compared on their merits.

Also, I certainly do not claim that the phenomena listed above do not exist! I claim only that to use the term "consciousness" for all of them leads to quite a bit of confusion.

\section{The Problem with "Consciousness"}

Let's start with "consciousness." My suggestion is that we 
not even use the word at all! We should avoid it if we can, not only because it is ambiguous but because it is misleading. "Consciousness," a noun, implies something fixed and substantial, but our experience is ever changing. There is no such thing as consciousness. One does not have consciousness as one has a shirt or a blouse or a coffee cup. Whenever we want to say "consciousness," I suggest, we instead try saying "being conscious" or some variant. And instead of "awareness" we should say "being aware." Doing so may not always work, but when it doesn't it will provoke us to be more specific about what we want to say.

\section{Definition is Difficult}

So what shall we mean by "being conscious"? In a pre-theoretical way we all know what it is to be conscious, because we are all conscious a good bit of the time. We have what is called "knowledge by acquaintance" (James, 1890, p. 221; James, 1963, p. 27; Russell, 1911) of being conscious. But attempts to define being conscious have been legion, and so far there is little agreement. That's because our language is inadequate to the task. Language is well-suited for talking about the objective world we all inhabit, but not our subjective experience.

Defining one of these terms ("mind," "consciousness," "awareness," "experience," etc.) by reference to the others does not solve the problem. We've known ever since Plato that defining words in terms of other words whose meaning is unclear just won't do

(Plato, Meno, 75b - 75d). At some point the chain of definitions needs to be grounded in an ostensive definition, something we can point at and say "This is what I mean by ' $\mathrm{X}$ '." But how do we give an ostensive definition of "being conscious," "being aware" and the like? Their referents are not something we can point at.

Herein I propose to solve this problem by starting with an operational definition of that which underlies all of the terms in question, the distinction between subjectivity and objectivity. What follows may seem elementary and obvious, but for completeness and maximum clarity we need to start here.

\section{A Starting Point: Subjectivity}

To elucidate the distinction between what is subjective and what is objective, think of the following scenario:

Two people - let's call them Alice and Bob - each think of a word or a color or an object without saying out loud what it is. Each knows only his or her own thought, not the other's. Alice does not and cannot know directly what Bob is thinking; and Bob, unless he is quite an unusual person with telepathic powers, cannot know what Alice is thinking. But both of them can look at a physical object such as a coffee cup, talk about it and agree on its color and shape.

This scenario illustrates the difference between what is subjective and what is objective. By "subjective" I mean what is private to each one of us. The things that Alice and Bob think of silently are subjective. By "objective" I mean what is out in the public world that we can all see or hear or touch or sense in some way. The color and shape of what they both see are objective.

Here are more formal definitions:

- By subjective I mean directly detectable or observable in principle by only one person, the person detecting or observing his or her world.

- By its opposite, objective, I mean detectable or observable by more than one person.

Some synonyms for "subjective" are "private," "hidden" and "interior." Some synonyms for "objective" are "public," "exposed," and "exterior." The idea is that some things of which each of us is conscious are not directly observable by anybody else, such things as our thoughts and feelings, the particular shades of colors we see and the particular qualities of sounds that we hear. These things are subjective. Others, like the color and shape of the agreed-upon object, are objective.

\section{Proposed Definitions}

With that fundamental distinction established, we can go on to consider the other terms commonly in use. "Experience," "being conscious," "mind," "being aware," "sentience" and other such terms all have to do with the subjective aspect of our life. Each has different connotations, however.

\section{Experience}

Of all the concepts relating to mind, I propose that we use experience as the most inclusive. It shall mean the subjective aspect of a person's taking into account his or her world.

This definition of experience - as that aspect of a person's taking into account his or her world which is detectable or observable in principle by that person alone-is a bit circular. Detecting and observing are, if not synonyms for experience, perhaps types of experience. That is unavoidable. Our language is oriented to the objective world, and it is difficult to use it to describe subjectivity.

At any rate, I propose to use "experience" as the broadest category, including everything on a spectrum from being awake, focused and alertly paying attention to something to hazily and dimly having a feeling in the background of experience, even so far in the background that it is not present to our attention at all. The latter is what some call "non-conscious experience" (Dewart, 1989, p.41; Nixon, 2014).

"Experience" in this sense includes both the process of experiencing and the objects experienced. The nature of the process is a matter for empirical phenomenological investigation, not definition, so in what follows I focus on the 
objects.

Please refer to Figure 1 below. We can think of what we experience as being on a continuum from vividly intense and in focus to dim and in a sort of periphery or penumbra, and in fact all the way to being not present at all. The focal end I call "conscious." I use the term "aware" for the entire spectrum of things that are present to us, but particularly the dim end. I use "unconscious" to mean those things that are not present but potentially could be, and, when they are, we recognize as subjective.

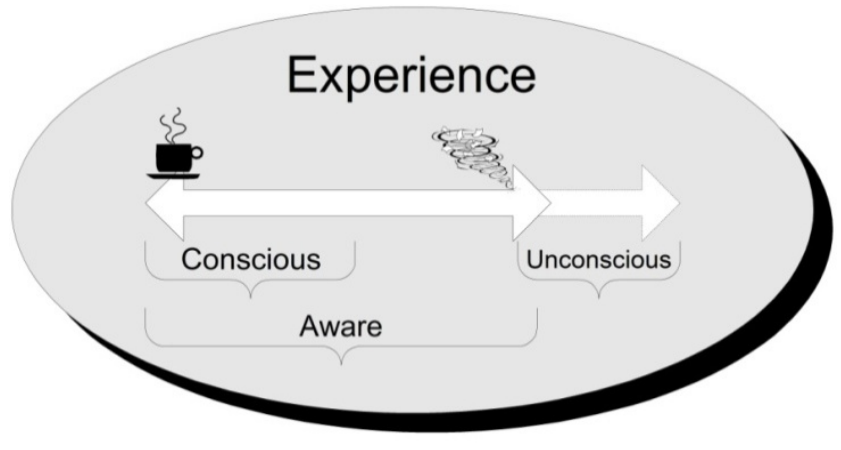

Figure 1. The Spectrum of Experience

More broadly, "experience" denotes everything that appears to a person. "An experience" means everything that appears to one at a single moment or over a short period of time; it is a sequence of lived events that has some unity. "The stream of experience" denotes everything that appears to one over a longer period of time; it connotes change, movement and process. The term "experience" can also mean one's experiences considered cumulatively, as in "Experience shows that such-and-such is the case." The term is also used as a verb. "One experiences something" means that one is aware of it in some way.

But what does it mean to be aware? Is being aware the same as being conscious? In the way I propose to use the terms, the two are different.

\section{Being Conscious}

The English language has two terms that mean roughly the same thing, "conscious" and "aware." The former is from a Latin root and the latter from Old Saxon (Dictionary.com, 2016). Many other languages have only one: "bewusst" in German, "conscient" in French, "consciente" in Spanish and Portuguese, for instance. Given this embarrassment of riches in English, it seems useful to make a distinction between the two terms. (Again, this is merely my recommendation, not an assertion about what the words must mean or in fact do mean in ordinary language.)

The term being conscious shall refer to a subset of experience, that subset in which objects are presented vividly and are in focus. As I have noted, rather than "consciousness" I suggest we use the phrase "being conscious" instead. We can say, if we need a noun, that consciousness is a state of being conscious or the capacity for being conscious.
Being conscious involves at least the following:

- The world is presented to one ${ }^{1}$ focally, with vividness or intensity; in other words, one notices or pays attention to some aspect of the world.

- Additionally, it may make sense to say that being conscious also involves two other characteristics:

- At the same time that one notices or pays attention to something, at some level one thinks about what one is noticing.

- All this happens with sufficient intensity to leave a memory for one.

(The terms "conscious" and "aware" most often refer to a person - or animal, perhaps - who is conscious or aware of something. But sometimes they refer to what the person is conscious or aware of, particularly when it is subjective. We say "a conscious thought" or "a conscious belief" meaning that the person entertaining the thought or belief is conscious of it. As the latter usage is derivative from the former, in what follows I focus on the former.)

1) Vividness

Many of the objects in our experience are present to us in rich detail, particularly those we focus on. Such objects are generally clear, distinct and vivid, and they are present focally. Many others are not. I recommend that we use the term "conscious" and its variants to refer to the former and "aware" and its variants to the latter.

2) Thought

Phenomenological investigation leads me to believe that being conscious includes at the same time both noticing or attending to some aspect of the world and having some mental representation, some dim thought, of it. Being conscious happens when attention is focused on something - that is, something is present vividly — and at the same time there is some idea of that same thing. There is a contrast between what is presented and one's idea. Without the idea, there is experience, but it is not memorable enough to be called conscious experience. I think it makes sense to

1 In these sentences "one" is intended to refer indefinitely to any person or, alternatively, to all persons. Thus they could be restated as follows:

- $\quad$ The world is presented to a person with vividness or intensity; in other words, that person notices some aspect of the world.

- At the same time at some level that person thinks about what he or she is noticing;.

- All this happens with sufficient intensity to leave a memory for that person.

I could restate the criteria for being conscious using the colloquial "you" as follows:

Being conscious entails that

- The world is presented to you with vividness or intensity; in other words, you notice some aspect of the world.

- At the same time at some level you think about what you are noticing.

- All this happens with sufficient intensity to leave a memory for you.

To see if these criteria make sense to you, substitute "me" or "I," as follows: Being conscious entails the following:

- $\quad$ The world is presented to me with vividness or intensity; in other words, I notice some aspect of the world.

- At the same time at some level I think about what I am noticing.

- All this happens with sufficient intensity to leave a memory for me. 
include such mental representation in the definition of "being conscious."

\section{3) Memory}

The way I propose to use the phrase, being conscious involves leaving a memory. I am open to suggestion as to whether leaving a memory would better be regarded as part of the definition of being conscious or as an effect of being conscious defined simply as vivid and intense experience.

Memory can take many forms. One might have quite a distinct memory of a song that jingles on in one's mind and refuses to disappear long after one has stopped hearing it. One may have olfactory experiences that leave a general memory of having smelled something familiar, but no specific memory of smelling exactly that smell. One may have a visual experience that leaves a general spatial memory, so that when trying to recall the situation, one "sees" oneself in the scene. No doubt there are more. But all these types of memory arise from being conscious. On my proposal, if an experience is not vivid enough to leave a memory, I do not call that experience conscious.

Of course memories fade with time. Being conscious does not necessarily leave an indelible or unfading memory.

The reason I think memory should be regarded as integral to being conscious is that sometimes we are obviously aware of our environment but later have no memory of the details. In such cases I prefer to avoid the phrase "being conscious" and instead use "being aware."

I was once put under the influence of the drug midazolam, which causes a loss of ability to create new memories (Drugs.com, 2015). I was in a dentist's office reading a magazine while waiting to undergo a procedure. A nice lady gave me a small pill to swallow with some water, and I continued reading. The next thing I knew, my wife was helping me stumble out of my car and into my house, where I fell into bed. I have no memory of what happened in between. I'm told that I was responsive to commands to get up and walk to the dental chair, that I opened and closed my mouth as directed and gave coherent replies to questions. But I have no memory of that time at all. Was I conscious while under the influence of the drug? As I define the terms, I would rather say that I was not conscious, but only aware.

\section{Being Aware}

Being acutely conscious is one end of a spectrum of kinds of experience. I use the term being aware for the entire spectrum, but particularly the less vivid and acute end. ${ }^{2}$ At one end of the spectrum we speak of being consciously aware of something; at the other end, of being dimly aware.

To point out what I mean: until I called it to your attention, you were probably not conscious of the chair pressing against your seat and back, or, if you are standing, of the

2 Thus, "experience" and "being aware" mean the same in that they have the same extension. Their connotations are different in that "being aware," when contrasted with "being conscious," refers particularly to the less vivid and intense elements in experience. floor or ground pressing against your feet. You were not conscious of it in the sense of attending to it; but nevertheless you were aware of it in the sense that it was present in your experience. Now that you are conscious of it, you recognize that the sensation or feeling of the chair or the floor, which was and is directly observable only by you, was present all along even when you did not notice it.

There are other examples. During highway hypnosis, when a driver is unable to recall specific moments or events during extended periods of driving, the driver is aware of - in the sense of being responsive to-his or her surroundings, the other cars on the road, the turns and intersections and so forth. But it would be a stretch to say that the driver is conscious.

There is much more present in any moment of experience than what is focally attended to; with William James, it is "the reinstatement of the vague and inarticulate to its proper place in our mental life which I am so anxious to press on the attention" (James, 1963, p. 157). Clear and distinct perception is not the only form of being aware; in fact is it only one end of a continuum, at the other end of which are vague and indistinct presentations, emotional and physical feelings, and finally subliminally or subconsciously presented objects of which we can only with the greatest of difficulty become explicitly conscious. I would like to reserve "conscious" for the clearer, more vivid and distinct end and use "aware" for the whole continuum.

\section{Mind and the Mental}

"Mind" is to be used to mean subjective experience, that is, experience of subjective things. As I use the terms, "mind" is equivalent to "that which is subjective," or "subjectivity," and "mental" is equivalent to "subjective." This may appear to be a dreadful oversimplification that omits the functional characteristics of mind, but I mean only to frame the discussion in a broad way from a first-person point of view. "Sentience" refers to experience that is primarily through the senses of sight, hearing, touch, smell and taste.

\section{Directedness (Intentionality)}

Being conscious and being aware always entail being conscious or aware of something. We are conscious of whatever appears to us, which might be objective or subjective. It might be objects that we take to exist in the real world; or it might be thoughts or emotions that we take to be private to us and not directly perceivable by anybody else; or it might be objects that we (later) take to be elements in a dream; or it might be physical feelings such as an itch that we take to be private to us; or it might be logical or mathematical constructs that we either take to be private to us or to be existent apart from us, although not in a physical way, depending on our philosophical theories about them. This is not an exhaustive list. There are a great many categories of things (using the term "thing" loosely) that we can be conscious of. 
This "ofness" is called "intentionality" in the philosophical literature. (I speak of experiential intentionality, not the intentionality of propositions, which is a related but different matter.) It would better be called "directedness" or "ofness." The meaning of "intention" is different from its meaning in ordinary usage. "Intention" ordinarily means one's plan to make something happen, including some degree of determination to make it happen and thus some amount of thinking about how to accomplish it. The technical term, however, means that capacity of the mind by which mental states refer to, or are about, or are of objects and states of affairs other than themselves (Searle, 2004, p. 28). Daniel Dennett explains it as follows:

The standard philosophical term for aboutness is intentionality, and ... it 'comes by metaphor' from the Latin intendere arcum in, which means to aim a bow and arrow at (something) (Dennett, 1991, p. 333).

Mental states are directed toward their objects as a bow directs an arrow toward a target.

\section{Container and Contents}

Directedness has two poles: that which is aimed (the arrow), and that which is aimed at (the target). Unfortunately, the term "consciousness" has been used for both. Metaphorically, the former is like a container and the latter is like its contents.

James alludes to the former when he says "Within each personal consciousness, thought is sensibly continuous" (James, 1963, p. 151). What he calls "personal consciousness," which I prefer to call "experience" or "mind," has things such as thought within it, so it is like a container. $\mathrm{He}$ alludes to the latter when he says "Consciousness is in constant change" (James, 1963, p.148). He means that the things of which we are conscious are always changing; they are like contents. That which is conscious is the container. What we are conscious of is the contents.

I bring this up because it is one of the most prevalent ways in which language about subjectivity can be confusing. For clarity, we need make explicit which sense we mean in any given context. When we mean the objects of which we are aware, let's use the words "objects" or "contents" rather than "consciousness" or "awareness."

\section{That which Experiences}

We also need a name for that which aims. What shall we call that which experiences, that which is aware (of whatever it is aware of)? The exact nature of what experiences is a matter of some import. We often take it to be ourselves; that is, each one of us, when asked "who experiences?" answers "I do." But the nature of the self that experiences is not something that can be determined by definition. It needs some investigation. We might call it the "experiencing subject." Following Kant, we might call it the "Transcendental Self" or the "Transcendental Ego," where "transcendental" means lying at the base or root of experience such that without such an ego there would be no experience at all. Edmund Husserl, the father of
Phenomenology, speaks of the "pure Ego," "the phenomenological Ego which finds things presented to it ..." (Husserl, 1967, p. 156). In any case, my recommendation is that we not use the ambiguous term "consciousness" to mean that which experiences.

\section{Reframing Confusing Language}

With these definitions in mind, we can now examine many common usages of "conscious," "aware" and so forth, with a view to reframing those that may engender confusion. Then we can address two related issues of language.

\section{Being Conscious}

We can clarify a number of confusing usages of the term "consciousness" simply by avoiding that term and saying something more precise instead. To do so, we need to understand the different meanings of the term. A good list is provided by neurologist Adam Zeman, who says that the origin of the term is the Latin scio, meaning "I know" and cum, "with". This implies that consciousness is "knowledge with," shared knowledge, knowledge shared with another person or knowledge shared with yourself, as when you talk to yourself (Zeman, 2002, p. 15). This etymology supports my contention above that being conscious of something always includes some element of ideation about the object of which one is conscious.

Zeman's first sense of the term "conscious" is simply being awake. The doctor asks the nurse whether the patient is conscious, meaning whether he or she is able to make an integrated response to the environment. This meaning need not confuse anyone, so long as the context is clear, but for precision we can use other words:

\begin{tabular}{|c|c|}
\hline Ambiguous language & Rephrased language \\
\hline conscious & Awake not sedated \\
\hline
\end{tabular}

Zeman's second sense of "conscious" is being aware. To be conscious is to be aware of something. In this sense, "consciousness" is ordinary experience. I suggest using the term "experience" instead of "consciousness."

As noted previously, one of the most prevalent ambiguities is that of consciousness as a kind of content versus as a kind of container. Zeman quotes William James in Principles of Psychology, as saying that consciousness is "the current content of perceptual experience" (Zeman, 2002, p. 18). However-and here is where the definition of the term gets slippery-sometimes the term "consciousness" means not the content but that which holds or includes the content. Consider phrases such as "It was not in my consciousness" and "expanding one's consciousness." Clearly the metaphor is that consciousness contains something else, and if consciousness is expanded it can contain more things or perhaps the same things more vividly.

The following table, largely taken from Zeman citing James, lists several characteristics of what is commonly called consciousness (Zeman, 2002, pp. 18-19). Alongside each one, I suggest a better way of saying it. 


\begin{tabular}{|c|c|}
\hline Ambiguous language & Rephrased language \\
\hline Consciousness is stable for short periods of time, up to a few seconds. & $\begin{array}{l}\text { What one is conscious of is stable for short periods of } \\
\text { time .... }\end{array}$ \\
\hline Consciousness is changeful over time. & What one is conscious of changes over time. \\
\hline Consciousness is selective, with a foreground and a background, and a limited capacity. & $\begin{array}{l}\text { Our ability to be conscious is selective and has a limited } \\
\text { capacity. } \\
\text { What we are conscious of includes a foreground and a } \\
\text { background. }\end{array}$ \\
\hline Attention can be directed, one can shift the focus of consciousness. & $\begin{array}{l}\text { Attention can be directed, one can shift the focus of } \\
\text { one's attending. }\end{array}$ \\
\hline Consciousness ranges over innumerable contents. & One can be conscious of innumerable contents. \\
\hline $\begin{array}{l}\text { Consciousness is continuous over time, in the sense that memory allows one to connect } \\
\text { what one is conscious of in the present with what one was conscious of in the past. }\end{array}$ & $\begin{array}{l}\text { Our sense of self is continuous over time } \ldots . . \\
\text { Our experience is continuous over time } \ldots . .\end{array}$ \\
\hline Consciousness is "intentional," in that it is of something, or directed at something. & $\begin{array}{l}\text { Being conscious is "intentional," in that when one is } \\
\text { conscious one is always conscious of something. }\end{array}$ \\
\hline $\begin{array}{l}\text { Consciousness is aspectual, with a limited point of view, conditioned by the perspective } \\
\text { of one's viewpoint. }\end{array}$ & $\begin{array}{l}\text { We experience only aspects of things. Each of us has a } \\
\text { limited point of view .... }\end{array}$ \\
\hline Consciousness is personal, involving a subject. & $\begin{array}{l}\text { We each have a sense that our experience is ours alone, } \\
\text { not someone else's. }\end{array}$ \\
\hline It was not in my consciousness. & $\begin{array}{l}\text { I was not conscious of it. } \\
\text { I did not think of it. } \\
\text { I did not notice it. }\end{array}$ \\
\hline My consciousness was expanded. & $\begin{array}{l}\text { Things appeared more intensely to me. } \\
\text { I had a greater understanding of things. }\end{array}$ \\
\hline
\end{tabular}

Yet another meaning of the term "consciousness" according to Zeman is mind or the subjective, interior aspect of the human being. He says"...'conscious' in this third sense can be used to report our acquaintance with any state of affairs whatsoever ...", whether public or private (Zeman, 2002, p. 20). Again, I recommend we say "aware" instead of "conscious," in order to include objects that are dim, vague or not in focus. In this sense one is aware of anything that passes through one's mind, and the term "aware" means "knowing". This kind of knowledge is knowledge by acquaintance (James, 1890, p. 221; James, 1963, p. 27; Russell, 1911), not theoretical knowledge.

\begin{tabular}{|c|c|}
\hline Ambiguous language & Rephrased language \\
\hline consciousness & Mind subjectivity \\
\hline
\end{tabular}

Being conscious can be related to intentions and purposes, as in "a conscious attempt to influence the proceedings" (Zeman, 2002, p. 21). Being conscious in this sense is linked with volition, the act of willing, or its outcome, deliberate action. It bridges perception and action. One does something deliberately when one knows that one is doing it and plans and intends to do it. Such knowledge is knowledge about, not knowledge by acquaintance only. We can rephrase such talk as follows:

\begin{tabular}{|c|c|}
\hline Ambiguous language & Rephrased language \\
\hline $\begin{array}{c}\text { a conscious attempt to influence } \\
\text { the proceedings }\end{array}$ & $\begin{array}{c}\text { a deliberate attempt to influence } \\
\text { the proceedings }\end{array}$ \\
\hline
\end{tabular}

Another meaning is the way one interprets one's world in a more global sense, particularly politically. Marxists talk about "bourgeois consciousness" or "proletarian consciousness," meaning the categories people in those economic classes use to think about economic or political events or their place in the social order, particularly if those categories are not examined but instead are used uncritically.
In this sense "consciousness" refers to characteristics of the container. The container is like a filter or colored lens, such that one pays more attention to certain contents than to others without realizing that one is doing so. Instead of talking about class consciousness, it would be better to speak of how the social world appears to one who is bourgeois or proletarian.

\begin{tabular}{|c|c|}
\hline Ambiguous language & Rephrased language \\
\hline proletarian consciousness & proletarian view of the world \\
\hline
\end{tabular}

"Conscious" can mean capable of being conscious as I have defined it above; that is, capable of paying attention to the world. In this sense we can say that people are conscious beings even when they are deeply asleep.

The term may be used to refer to a conscious being such as a person or even a deity: "He could sense a consciousness somewhere in the distance" or "a vast consciousness watching over us." Such figurative speech-technically called synecdoche, using a part to represent the whole-is not at all how discussions of mind would use the term, however.

\begin{tabular}{|c|c|}
\hline Ambiguous language & Rephrased language \\
\hline a consciousness & a person; a living being \\
\hline
\end{tabular}

Finally, some mystical thinkers use "consciousness" to mean the ground of all being, that which underlies everything or from which everything emerges. For instance, Deepak Chopra, a prominent New Age author and speaker, says

consciousness creates reality (Chopra, 2009, Preface) and

Consciousness ... is not just a human attribute. 
Existing outside space and time, it was "there" "before" those two words had any meaning. In essence, space and time are conceptual artifacts that sprang from primordial consciousness (Roff, 2016).

Without addressing the metaphysical claim, it should be clear at least that the term "consciousness" in this context is misleading. Its meaning is certainly far from just being able to detect one's surroundings well enough to navigate around. As this primordial consciousness is alleged to precede any distinction between being conscious and what one is conscious of, it would be less confusing to call it something else, perhaps "primordial being" or "primordial reality."

\begin{tabular}{|c|c|}
\hline Ambiguous language & Rephrased language \\
\hline primordial consciousness & $\begin{array}{c}\text { primordial being } \\
\text { primordial reality }\end{array}$ \\
\hline
\end{tabular}

\section{Being Self-conscious}

The meanings of "self-consciousness" are as varied as the meanings of "consciousness."

Zeman helpfully lists several common meanings of the term "self-conscious" (Zeman, 2002, pp. 21-29). The first is awkward or prone to embarrassment. Self-consciousness is excessive sensitivity to the attention of others when it is directed towards us. An essential element of self-consciousness in this sense is knowing that others are conscious of us, which is knowledge about, although the feeling of embarrassment itself is known by acquaintance. This usage need not be confusing, so long as the context is clear and we say "being self-conscious" instead of "self-consciousness." When extreme clarity is needed, we can use other phrases, as follows:

\begin{tabular}{|c|c|}
\hline Ambiguous language & Rephrased language \\
\hline self-conscious & $\begin{array}{c}\text { overly sensitive to others } \\
\text { embarrassed }\end{array}$ \\
\hline
\end{tabular}

Another sense of "self-conscious" is self-detecting. We can detect things that are happening to us or are caused by us, as opposed to happening to or caused by someone else. We ascribe this knowledge in greater and greater degree to children as they grow out of infancy. The infant, we surmise, has little ability to detect what happens as a result of its own activity as opposed to someone else's. As children grow older they acquire the ability to be self-conscious in this sense.

\begin{tabular}{|c|c|}
\hline Ambiguous language & Rephrased language \\
\hline self-conscious & self-detecting \\
\hline $\begin{array}{c}\text { having } \\
\text { self-consciousness }\end{array}$ & $\begin{array}{l}\text { having the ability to discern one's activity } \\
\text { as one's own }\end{array}$ \\
\hline
\end{tabular}

An elaboration of this sense of being self-conscious is self-recognizing. When one is self-conscious, the contents of one's experience include a concept or idea of oneself, a self-representation. This gives rise, says Zeman, to second-order evaluative emotions such as envy, pride, guilt and shame, which require a sense (concept) of oneself as the object of others' attentions. (First-order emotions, such as joy, anger, sadness, interest, disgust and fear, do not presuppose any such self-representation.) We can avoid ambiguity as follows:

\begin{tabular}{|c|c|}
\hline Ambiguous language & Rephrased language \\
\hline self-conscious & $\begin{array}{c}\text { having ideas about oneself } \\
\text { thinking about oneself } \\
\text { being able to think about oneself }\end{array}$ \\
\hline
\end{tabular}

Having an idea of oneself, one can then pay attention to one's experience in a different way, knowing that it is subjective. This is another meaning of "self-conscious": knowing that one is conscious and paying attention, not just to the contents of consciousness - that is, to what we are conscious of - but to the fact of being conscious as well (which then becomes one of the things we are conscious of). One distinguishes between things that are open to public inspection, such as physical things, and things that are private, such as dreams. One conceives of oneself as a subject of experience, not just as a person being observed by others. One pays attention to the subjective contents of experience in addition to its other objects. This kind of being conscious of oneself happens in real time, so to speak, as experience is taking place.

\begin{tabular}{|c|c|}
\hline $\begin{array}{c}\text { Ambiguous } \\
\text { language }\end{array}$ & Rephrased language \\
\hline being self-conscious & being directly or immediately conscious of \\
oneself
\end{tabular}

Finally, we can speak of being self-conscious in a broader sense as having self-knowledge, knowledge of the entire psychological and social context in which one comes to know oneself. If this is what we mean, let's say that one has self-knowledge or that one knows oneself. Because "self-conscious" often connotes social awkwardness, I sometimes say "self-aware" to mean the general ability to know oneself and to be directly conscious of oneself. (This is an exception to the general recommendation of how to use "aware.")

\begin{tabular}{|c|c|}
\hline Ambiguous language & Rephrased language \\
\hline being self-conscious & $\begin{array}{c}\text { having self-knowledge } \\
\text { knowing oneself } \\
\text { being self-aware }\end{array}$ \\
\hline
\end{tabular}

\section{"What it is like"}

There are a couple of other issues in speaking of subjectivity that are potentially confusing. The first is the phrase "what it is like."

A friend of mine used to startle people by asking "So, what's it like being you?" Best answers:

- Fun!" (five year-old boy)

- " "Better than being you." (graduate student, now director of corporate strategy at a large enterprise)

- "I don't know, I have no basis for comparison." (university professor)

Humorous as these answers may be, only the last one is philosophically accurate. Ever since Nagel's influential 
essay "What Is It Like To Be A Bat?" the phrase "what it is like" has been used to refer to the subjective character of being conscious. An influential article on Phenomenology, for instance, contains the phrase "what it is like to have sensations of various kinds" (Smith, 2015). The famous Zombie Argument against the reducibility of the mental to the physical asserts "There is nothing it is like to be a zombie" (Chalmers, 2013). The Routledge Encyclopaedia of Philosophy tells us, "An experience or other mental entity is 'phenomenally conscious' just in case there is something it is like for one to have it" (Lomand, 1998, p. 581). Other examples abound. But it is a very misleading phrase, because strictly speaking one's subjectivity is not like anything!

In order for the phrase "what it is like" to make sense, it has to refer to something we can contrast to something else (Garvey, 2010, pp. 28-29). We can ask what it is like to swim in an ocean and answer by comparing swimming in an ocean to swimming in a lake. But to ask what it is like to be conscious or to have sensations makes no sense, because there is nothing to which we can contrast being conscious or having sensations. Each of us has his or her own experience alone. Nobody else has direct access to it, nor have we direct access to anyone else's, so we can't compare them and can't truly assert similarity or difference. We can compare our present experience to memories of our own past experience or anticipations of our future experience. But our experience is not like anything, in the way, for instance, that the flavor of a tangelo is a bit like that of a tangerine but juicier and a bit like that of a grapefruit but sweeter.

Nagel himself recognized the difficulty. He says "The analogical form of the English expression 'what it is like' is misleading. It does not mean 'what (in our experience) it resembles', but rather 'how it is for the subject himself" (Nagel, 1974, footnote 6). Nagel's essay would have been better titled "How It Is To Be A Bat."

In everyday speech it may be quite OK to use the phrase "what it is like" to refer to our subjectivity, because it is an idiom that we generally understand. But even so, it lacks a certain panache. Bob Dylan did not sing "What is it like? / To be on your own / Like a rolling stone."

In philosophical speech, however, such idiomatic language is best avoided. It leads to sophomoric conundrums like how I can tell whether my experience of redness is the same as yours. (Answer: I can't, and it doesn't matter.) Let's quit using the expression "what it is like" to speak of subjectivity and speak instead of how it is or how it feels to be conscious. The issue concerns more than just arcane discussions in philosophy of mind. It is a crucial question in the age-old and perennially new question of how we can know ourselves. Wisdom is not served by verbal confusion.

\begin{tabular}{|c|c|}
\hline Ambiguous language & Rephrased language \\
\hline what it is like to be conscious & $\begin{array}{c}\text { how it is to be conscious } \\
\text { how it feels to be conscious }\end{array}$ \\
\hline
\end{tabular}

\section{First-person grammar}

Another issue is the use of the grammatical first person. A great many authors use the grammatical first person to speak of observations made from a first-person point of view, but they mean to assert things that are true of everyone, not just them alone. This usage can lead to confusion. Consider the following two sentences, both from the same author:

I have a privileged perspective on what it feels like to be me that is not available to anyone else ....

I understand that Searle resists the label [property dualism], but much of what he says surely presupposes such a position (Caldwell, 2006).

It is clear from the context that the first sentence is meant to apply to everyone and the second is a statement about the author's understanding alone, not everyone's. But sometimes the context is ambiguous. At one point Daniel Dennett says this:

As a left-handed person, I can wonder whether I am a left-hemisphere-dominant speaker or a right-hemisphere-dominant speaker, and the only way I can learn the truth is by submitting myself to objective, 'third-person' testing. ... [T] here are, however, some events that occur in my brain that I do know about, as soon as they occur: my subjective experiences themselves (Dennett, 2005, pp. 77,78$)$.

Does Dennett speak autobiographically or generally? Or does he mix the two modes in the same paragraph?

I respectfully suggest that we avoid the grammatical first person when we really mean to assert something applicable generally. It's not hard to do. We can say "each of us" or "one" instead of "I," as follows:

\begin{tabular}{|c|c|}
\hline Ambiguous language & Rephrased language \\
\hline $\begin{array}{c}\text { I have a privileged } \\
\text { perspective on how it feels } \\
\text { to be me. }\end{array}$ & $\begin{array}{c}\text { Each of us has a privileged perspective } \\
\text { on how it feels to be the person that we } \\
\text { are. }\end{array}$ \\
\hline $\begin{array}{c}\text { If I think I am conscious, } \\
\text { then I am conscious, }\end{array}$ & $\begin{array}{c}\text { If one thinks one is conscious, then one } \\
\text { is conscious. }\end{array}$ \\
\hline
\end{tabular}

\section{Conclusions}

This concludes my recommendations for using unambiguous language about subjectivity. If we mutually agree on using words in a standard way, we can make headway on the substantive issues in philosophy of mind, cognitive science, neurophysiology and so forth.

Some may well object to my suggestions. The term "consciousness" is central to psychology and much of philosophy. If my suggestions create confusion, I hope only that it will be less confusion than already exists.

Finally, if it is important to know ourselves, as Socrates and the Oracle at Delphi advised, then being able to speak without ambiguity about mind, experience, consciousness and so forth is not just a good intellectual exercise. It is important for self-understanding and hence for self-improvement as well. 


\section{REFERENCES}

[1] Caldwell, Roger. (2006). "How to be Conscious." Philosophy Now magazine Number 54. [Online] https://philosophynow.o $\mathrm{rg} / \mathrm{issues} / 54$ [25 May 2006].

[2] Chalmers, David. "Zombies on the web." (2013). [Online] http://consc.net/zombies.html [21 August 2013].

[3] Chopra, Deepak. (2009 [1989]). Quantum Healing: Exploring the Frontiers of Mind Body Medicine. New York: Random House.

[4] Dennett, Daniel C. (1991). Consciousness Explained. Boston: Little, Brown and Company Back Bay Books.

[5] Dennett, Daniel C. (2005). Sweet Dreams: Philosophical Obstacles to a Science of Consciousness. Cambridge, MA: The MIT Press.

[6] Dewart, Leslie. (1989). Evolution and Consciousness: The Role of Speech in the Origin and Development of Human Nature. Toronto: University of Toronto Press.

[7] Dictionary.com. (2016). [Online]http://www.dictionary.com/ browse/conscious and http://www.dictionary.com/browse/aware [4 May 2016].

[8] Drugs.com. (2015). "Versed." [Online] http://www.drugs.co m/cons/versed.html [29 October 2015].

[9] Garvey, James. "Hacker's Challenge." (2010). TPM, The Philosopher's Magazine, Issue 51, 4th Quarter 2010, pp. 24-32. [Online] http://jamesgarveyactually.files.wordpress.c om/2011/03/hackers-challenge.pdf [6 October 2014].

[10] Husserl, Edmund. (1967). Ideas: General Introduction to Pure Phenomenology. Tr. W. R. Boyce Gibson. New York: Collier Books.

[11] James, William. (1890). Principles of Psychology, Vol. 1. New York: Holt.

[12] James, William. (1963). Psychology. (Briefer Course).
Premier Books. Greenwich, Connecticut: Fawcett Publicatio ns.

[13] Lomand, E. (1998). "Consciousness." Routledge Encyclopaedia of Philosophy, vol. 2. London: Routledge.

[14] Nagel, Thomas. (1974). "What Is It Like To Be A Bat?" The Philosophical Review, Vol. 83, No. 4, pp. 435-450. [Online] http://www.jstor.org/stable/2183914 [29 April 2015].

[15] Nixon, Gregory. (2014). "From Panexperientialism to Conscious Experience." [Online] https://www.academia.edu/ 295126/ From Panexperientialism to Conscious Experien ce_The_Continuum_of_Experience_[ 8 - August 2014].

[16] Plato. Meno. In Plato: The Collected Dialogues. ed. Edith Hamilton and Huntington Cairns. (1963). New York: Pantheon Books.

[17] Roff, Chelsea. (2016). "Interview with Deepak Chopra on Consciousness, God, \& the Nature of Belief." [Online] http://www.beliefnet.com/columnists/intentchopra/2012/09/i nterview-with-deepak-chopra-on-consciousness-god-the-nat ure-of-belief.html [5 May 2016].

[18] Russell, Bertrand. (1911). "Knowledge by Acquaintance and Knowledge by Description." Proceedings of the Aristotelian Society, 1910-1911. Reprinted in his Mysticism and Logic (London: George Allen \& Un win Ltd.: 1917). Reprinted Totowa, New Jersey: Barnes \& Noble Books, 1951, pp. 152-167. [Online]http://selfpace.uconn.edu/class/percep/Rus sellKnowAcquaint.pdf [26 June 2014].

[19] Searle, John R. (2004). Mind: A Brief Introduction. Oxford: Oxford University Press.

[20] Smith, David Woodruff. (2015). "Phenomenology." Stanford Encyclopedia of Philosophy (Winter 2013 Edition), Edward N. Zalta, ed. [Online] http://plato.stanford.edu/archives/win2 013/entries/phenomenology/ [26 October 2015].

[21] Zeman, Adam. (2002). Consciousness, A User's Guide. New Haven: Yale University Press. 